\title{
Media Predictors during the 2012 Presidential Election: Political Understanding, Discussion and Candidate Likeability
}

\author{
Thomas P. Boyle \\ Correspondence: Thomas P. Boyle, Ph.D., Department of Communication \& Theatre, Millersville University, P.O. Box \\ 1002, Millersville, PA 17551, USA.
}

Received: October 20, 2013 Accepted: November 7, $2013 \quad$ Available online: February 10, 2014

doi:10.11114/smc.v2i1.238

URL: http://dx.doi.org/10.11114/smc.v2i1.238

\begin{abstract}
This study examined the influence of traditional and online media variables on political understanding, discussion and likeability of the major 2012 U.S. presidential candidates. Political information seeking on web sites and blogs contributed to confidence in understanding political issues but not for reducing the complexity of government. All three online sources studied predicted increased interpersonal communication about politics, as did viewing television news and listening to radio news. Almost all of the media variables influenced evaluations of the major party candidates with some reducing positive evaluations and others increasing them. Exposure to radio news was a consistent predictor but varied based on measurement and candidate. Future studies should consider greater complexity of measures to consider type of discussion and social media.
\end{abstract}

Keywords: political communication, presidential campaigns, social media use, traditional media use, political understanding, political discussion

\section{Introduction}

Communication scholars have long considered the role of emerging technologies and their influence. Since web sites became commonplace, researchers have examined the potential of online communication to create a "one-step flow" allowing individuals to join larger dialogues without the need for traditional media tools (Bennett \& Manheim, 2006). Not surprisingly, media researchers have embraced the investigation of social media as another form of online communication with great potential to transform communication. The use of social media in the political sphere has continued to increase as noted by several studies conducted as part of the Pew Internet \& American Life Project (e.g. Rainie \& Smith, 2012). In early 2012, more than one in four indicated they use social media to encourage others, talk with or find those with congruent views about politics (Rainie \& Smith, 2012, p. 7). While the use of social media increases, it still has not displaced more traditional sources of political information for these activities (Rainie \& Smith, 2012, p. 7). Subsequent research during summer 2012 found more than a third of respondents used social media to share and promote their political views and voting for their political candidates (38 percent) (Rainie, Smith, Lehman Schlozman, Brady \& Verba, 2012, p. 4). Close to election day, respondents indicated that social media has become a powerful tool to receive and, in some cases, promote voting for one of the major party candidates (Rainie, 2012). Almost half of adults received these voting appeals through direct interpersonal communication, 48 percent, while social media appeals were received by 30 percent (Rainie, 2012, p. 3). The continued use of various types of online media requires renewed focus by scholars, along with investigating traditional media sources.

\subsection{Social and Traditional Media Scholarship}

The use of online communication in civic engagement by various communities has often been considered (e.g. Winograd \& Hais, 2008). Online messages were found to not directly influence the vote by younger adults but did lead to less substantive political activities (Hargittai \& Shaw, 2013, pp. 126-127, 130). Kaye and Johnson found "guidance, information seeking/surveillance, entertainment, and social utility" were the leading motivators for seeking political information on the web (2002, pp. 62-63). The credibility of online media has reached that or exceeds traditional media according to Johnson and Kaye (2010). Those media with the greater credibility, according to respondents of an online survey, were blogs and newspapers (print and electronic) (Johnson \& Kaye, 2010, p. 10). The biggest predictor of online media credibility was the respondent's use of that form of media - either online or in print (Johnson \& Kaye, 2010, pp. 11-14). For example, the more a respondent uses television the greater the credibility of web television (Johnson \& Kaye, 2010, p. 11). In a detailed analysis of blog use, Kaye and Johnson were able to put those who believed the most trusted blogs can be grouped four ways: "blog confidents ... war/corporate blog doubters ... war blog 
faithful ... blog averse" (2011, pp. 250-255).

Similarly, shortly after a major U.S. election, de Zuniga considered social media and found using it "may also facilitate community life beyond the strict measures of civic participation" (2012, p. 329). Metzgar and Maruggi found social media was not simply another media channel but rather provided the ability to continue the political interaction after it was received (2009, p. 160). They found with social media, in the 2008 U.S. presidential campaign, it was difficult to determine the origin of issue conversations between traditional and online communication because of the very similar media agendas $(2009$, p. 160). The researchers determined that despite a limited number of issues discussed by the campaigns, social media created and promoted online communities that in previous decades may have been controlled by campaigns (Metzger \& Maruggi, 2009, pp. 160-161). Other researchers found that individuals comfortable with expressing their political views were likely to use social media sites but not other online sources while those having "informational trust" with sources not family members or close friends would use various types of online media (Himelboim, Lariscy, Tinkham \& Sweetser, 2012, pp. 103-104, 107). During the 2006 national Dutch elections, Utz found that interactions on a major social networking site would lead to more individuals visiting candidate pages on the network $(2009$, p. 230). In a related experiment, the researchers found that candidate web information that reflected their response to public feedback led to higher evaluations of the political figure $(2009$, p. 235).

Specific forms of online media, like Twitter, have been explored by scholars (e.g. Houston, Hawthorne, Spialek, Greenwood, \& McKinney, 2013) and new forms of analytic tools have been developed for audience created messages whose format have not yet developed (Dylko \& McCluskey, 2012). In the 2012 election, the use of Twitter - both routinely and during the debates - was a predictor of candidate evaluations (Houston, et al., 2013). The researchers indicated the influence could be a result of the act of tweeting or the content being tweeted (Houston, et al., 2013, p. 308).

Aside from social media, communication researchers have explored traditional web sites. The author found that gathering information from news web sites increased interest in political issues, positive attributes of Obama and negatives ones of McCain (Boyle, 2013). Having an interest in campaigns led to using websites for political information during the 2008 presidential election (Parmelee, Davies \& McMahan, 2011). Using radio for news increased the likelihood of web site use for political information and information from sites not affiliated with a mainstream media outlet were most likely to be used by men (Parmelee, Davies \& McMahan, 2011, p. 634). Smith and Smith found respondents had positive evaluations of unknown female candidates by viewing their web pages even when they had opposing political orientations (2009).

Interpersonal communication, specifically political discussion, has also been considered by researchers for its role in furthering engagement (e.g. Tian, 2011). Moy and Gastil considered behaviors that might influence "deliberative conversation" that encourages participants to "embrace conflict" and "reach meaningful judgments on public issues" (2006, p. 445). The researchers found that mere conversation does not add to this type of behavior. Moy and Gastil did find that newspaper reading led to a greater acceptance of views not congruent with their own and gathering news from television resulted in varying support for the "deliberative conversation" items (2006, pp. 452, 454-455). Using national survey data from Japan, Ikeda and Boase (2011) report that regardless of the communication context and whether similar or opposing viewpoints were discussed, political discussion predicted campaign and similar involvement ( $\mathrm{pp}$. 676-677). Exposure to opposing viewpoints lowered candidate policy learning by individuals who discussed politics during the 2000 presidential campaign (Feldman \& Price, 2008, p. 75). In addition, the combined influence of political talk, exposure to opposing viewpoints, and watching the debate would also lower learning about the policy stands of the candidates (Feldman \& Price, 2008, p. 77). Beyond policy information, the researchers found no support that talking politics increased learning about the candidate's previous life experiences (Feldman \& Price, 2008, p. 75). Researchers continued to explore different forms of political discussion as well, with one study finding that shortly after the 2004 election different discussions contributed differently to their predictive ability for candidate knowledge and campaign activities (Eveland \& Hutchens Hively, 2009). Additional exploration by Morey, Eveland and Hutchens indicates that when discussing issues with close confidants existing knowledge and how often you engage interpersonally contribute to holding similar political views while the amount of general political discussion with everyone reduces those odds (2012, p. 95). Eveland, Morey and Hutchens authored an extensive theoretical review of the role of political talk and indicate scholars have typically focused on three areas: context, willingness to engage opposing viewpoints, and the influence of political discussion on other political activities (Eveland, Morey \& Hutchens, 2011, pp. 1083-85, 1096-97).

Tian considered the predictors of political discussion as a prelude to political involvement $(2011$, p. 390). The researcher found internet and traditional media use led to a greater discussion of politics and political interest led to increased campaign communication (2012, pp. 389-390). Interesting, Tian found support for the belief that these discussions promote other political activity and helps "to mediate between political media use and political participation" possibly leading to greater comprehension (2012, p. 392). The same role for talking politics was found by others who conducted telephone surveys in Germany from 2002-2010 (Emmer, Wolling \& Vowe, 2012, p. 249). The researchers found online discussions followed online political messages and non-electronic discussions followed 
traditional political messages (Emmer, Wolling \& Vowe, 2012, p. 243). Major campaign events were also determined to generate additional political talk by respondents during the 2004 U.S. presidential election (Hardy \& Scheufele, 2009, p. 95). Regardless of this increase, discussion of politics led to fewer respondents being able to correctly identify where the major candidates stood on policy issue stands (Hardy \& Scheufele, 2009, p. 97). Himelboim, Lariscy, Tinkham and Sweetser found that having "informational trust" with sources from non-family members was associated with having an interest in direct and online political discussions (2012, pp. 104-105). Eveland found more than one motivating factor "mediates the effect of interpersonal political communication" (2004, p. 189).

\subsection{Research Questions}

With a continued focus on interpersonal, traditional and social media, the following questions were explored in the 2012 election study below.

RQ1: Does following the presidential election online increase political understanding?

RQ2: Does online news gathering increase political understanding more than traditional media use?

RQ3: Does following the presidential election online increase political discussion?

RQ4: Does online news gathering increase political discussion more than traditional media use?

RQ5: Does following the presidential election online increase candidate likeability?

RQ6: Does online news gathering increase candidate likeability more than traditional media use?

\section{Methods}

The data used for this study is from the American National Election Studies 2012 Time Series Study preliminary release utilizing telephone and web surveys with more than 5,900 respondents (ANES, 2013, p. 5; see http://www.electionstudies.org). The data set used for the analysis is a continuation of time series survey collection begun with the 1948 presidential election (ANES, 2013). The survey questions and procedures have been scrutinized regularly and updated as appropriate. Consequently, the survey items are systematic and have a high degree of validity (for additional information, see ANES 2012, pp. 5-8).

Demographic variables used for the analysis are: gender, age, race, education, and income. The gender and race items were recoded to create dichotomous variables. When appropriate, other variables were recoded to allow the higher attribute (e.g. "always" in attention to politics) to have the highest numerical value to facilitate comparison. Along with standard demographic variables, attention to politics and campaign interest were also studied. Attention to politics was measured with a five-point scale ("never" to "always") and campaign interest with a three-point scale ("not much interested" to "very much interested") (ANES, 2013).

Media variables were measured as "days in typical week" that respondents read, listened, watched or interacted. This block of variables were: print, television news, radio news and web news sites. Also, for the first time exposure to social media and blogs was measured by ANES (2013, p. 14).

The dependent variables were political comprehension, political discussion and feeling thermometer for the major party candidates. Political comprehension was measured by two survey items: "How often do politics and government seem so complicated that you can't really understand what's going on?" and "How well do you understand the important political issues facing our country?" both measured on a five-point scale ranging from "never" to "always" and "not well at all" to "extremely well" (ANES, 2013, pp. 1533, 1535). Political discussion was measured by the number of days in the past week respondent discussed politics. Likeability of the candidates was measured by where on a 100-point "feeling thermometer" respondents would rate the major party candidates (ANES, 2013, pp. 1179-1180).

\section{Results}

Least squares regression is often used to consider the impact of demographic and other variables on political action (e.g. Weaver \& Drew, 2001). All regression analyses were weighted for the full sample to allow generalizability (see ANES, 2013, pp. 32-37). Research questions one and two focus media influences on political understanding, research questions three and four focus on media influences on political discussion, and the final two questions focus on media predictors of liking major party candidates.

\subsection{Research Questions One and Two}

RQ1: Does following the presidential election online increase political understanding?

RQ2: Does online news gathering increase political understanding more than traditional media use?

Table one shows the demographic and media predictors of political comprehension. When considering whether respondents believed "politics and government seem so complicated," gender, age and income were three statistically significant but small demographic variables (ANES, 2013, p. 1533). Being female and an older Americans would add to 
political affairs being too complicated while those with higher incomes would feel less likely to indicate politics is complicated. The standardized coefficient indicating paying attention to politics had the largest explanatory power in the model $(=-.22)$ with interest in the campaign also being significant at $(=-.15)$. Not surprising, individuals interested and attentive to politics and governmental affairs were less likely to indicate the political sphere is too complicated. Overall, the block of demographic and political/campaign attention variables had a significant coefficient of multiple determination (adjusted R-square) of .14.

3.2 Table 1. Hierarchical Regression Analysis for 2012 Political Comprehension and Discussion Regressed on Demographics, Social and other Media Variables

\begin{tabular}{|c|c|c|c|c|c|c|}
\hline \multirow{4}{*}{ Independent Variables } & \multicolumn{6}{|c|}{ Dependent Variable } \\
\hline & \multicolumn{4}{|c|}{ Political Comprehension } & \multirow{2}{*}{\multicolumn{2}{|c|}{$\begin{array}{l}\text { Political Discussion } \\
\text { Politics Discussed }\end{array}$}} \\
\hline & \multicolumn{2}{|c|}{ Complicated } & \multicolumn{2}{|c|}{ Understanding } & & \\
\hline & $\beta$ & $\mathrm{b}$ & $\beta$ & $\mathrm{b}$ & $\beta$ & $\mathrm{b}$ \\
\hline \multicolumn{7}{|l|}{ Block 1: Demographics } \\
\hline Gender $(1=$ female $)$ & $.07 * * *$ & $.15 * * *$ & -.10 & -.20 & -.01 & -.05 \\
\hline Age & $.05 * *$ & $.02 * *$ & $-.01 * * *$ & $.00 * * *$ & .03 & .02 \\
\hline Race $(1=$ black $)$ & -.06 & -.19 & .00 & .00 & -.09 & -.58 \\
\hline Race $(1=$ hispanic $)$ & -.03 & -.11 & -.01 & -.01 & $-.08 * * *$ & $-.56 * * *$ \\
\hline Race (1=caucasian) & -.04 & -.09 & -.03 & -.05 & $-.09 * * *$ & $-.43 * * *$ \\
\hline Education & -.03 & -.02 & .01 & .00 & $.07 * *$ & $.06 * *$ \\
\hline Income & $-.11 * * *$ & $-.01 * * *$ & $.05 * *$ & $.01 * *$ & .02 & .01 \\
\hline Attention to Politics & $-.22 * * *$ & $-.21 * * *$ & $.42 * * *$ & $.36 * * *$ & $.27 * * *$ & $.53 * * *$ \\
\hline Campaign Interest & $-.15 * * *$ & $-.23 * * *$ & $.13 * * *$ & $.17 * * *$ & $.09 * * *$ & $.28 * * *$ \\
\hline Adjusted $\mathrm{R}^{2}$ & $.14 * * *$ & & $.29 * * *$ & & $.13 * * *$ & \\
\hline \multicolumn{7}{|l|}{ Block 2: Media Variables } \\
\hline Exposure to Print & $-.05 *$ & $-.02 *$ & .00 & .00 & .02 & .01 \\
\hline Exposure to TV News & $.09 * * *$ & $.04 * * *$ & .03 & .01 & $.07 * * *$ & $.05 * * *$ \\
\hline Exposure to Radio News & $-.07 * * *$ & $-.03 * * *$ & $.04 *$ & $.02 *$ & $.07 * * *$ & $.06 * * *$ \\
\hline Exposure to Web News Sites & -.04 & -.02 & $.05 * *$ & $.02 * *$ & $.06 * * *$ & $.04 * * *$ \\
\hline Exposure to Social/Election & .02 & .01 & .01 & .00 & $.04 * *$ & $.03 * *$ \\
\hline Exposure to Blogs/Election & -.02 & -.02 & $.06 * * *$ & $.06 * * *$ & $.07 * * *$ & $.12 * * *$ \\
\hline $\mathrm{R}^{2}$ Change & $.01 * * *$ & & $.01 * * *$ & & $.02 * * *$ & \\
\hline Total $\mathrm{R}^{2}$ & $.16 * * *$ & & $.31 * * *$ & & $.15 * * *$ & \\
\hline Adjusted $\mathrm{R}^{2}$ & $.15 * * *$ & & $.30 * * *$ & & $.15 * * *$ & \\
\hline
\end{tabular}

$[\beta=$ standardized coefficients, $b=$ unstandardized coefficients. Block one contains coefficients from weighted least squares regression analysis. Block two contains coefficients from the full model containing blocks one and two. Block one coefficients from the full model, although similar to those above, are not shown for purposes of brevity. Post-election $\mathrm{n}=5510 . \wedge \mathrm{p} \leqslant .10 \quad * \mathrm{p} \leqslant .05 \quad * * \mathrm{p} \leqslant .01 \quad * * * \mathrm{p} \leqslant .001$.

The weighted least squares model next adds the six media variables. Only the number of days respondents were exposed to television news and radio news are statistically significant but indicate different relationships. Those who regularly used television news were more likely to indicate they had difficulty understanding political matters (=.09) while those that were regularly exposed to radio news were less likely to indicate difficulty $(=-.07)$. The change in the R-square was significant but very small at .01 giving the overall model an adjusted R-square of .15.

The second model in table one shows the predictor variables for how well individuals understood important policy issues. Of the demographic variables in model two, age (= -.01) and income (=.05) were statistically significant but produced small regression coefficients. Much larger were the coefficients representing attention and interest with standardized coefficients of .42 and .13 respectively. For example, the model's unstandardized coefficient predicts that moving from "never" to "always" on the attention scale would increase someone's political understanding from "moderately well" to "very well" or some other one-step gain on the five-point scale. Again, we see small but significant contributions made by the addition of the media variables. Days of exposure to radio and online news had standardized coefficients of .04 and .05 while the predictor representing reading blogs about the election was .06. Based largely on the predictive nature of attention to politics for understanding, the adjusted R-squared of the complete model was .30.

The final model in table one attempts to identify predictor variables for the number of days respondents talk about politics (research questions three and four).

\subsection{Research Questions Three and Four}

RQ3: Does following the presidential election online increase political discussion? 
RQ4: Does online news gathering increase political discussion more than traditional media use?

In predicting days of discussed politics, race and education were the only two statistically significant variables in the model. According to the unstandardized coefficients those hispanic and caucasian were slightly less likely to talk about politics (= -.56) and (= -.43) respectively. As in all of the table one models, attention and interest in politics were statistically significant and the largest. Attention to politics was the largest standardize coefficient at .27 - the next largest was education at .07. Based on the unstandardized coefficient $(b=.53)$ for every two levels on the attention five-point scale would predict one more day during the week when the respondent would talk politics. Interest in the campaign had a statistically significant but smaller influence with an unstandardized coefficient of .28. Overall, the demographic and interest variables model had an adjusted R-square of .13. Of the six media variables, five were statistically significant and small. The standardized coefficient for television news, radio news, and blog reading was .07 while other online information gathering were also small, web news with a coefficient of .06 and social media with a coefficient of .04. The adjusted R-square of the full model was .15.

\subsection{Research Questions Five and Six}

Table two shows predictors on how respondents felt about Barack Obama and Mitt Romney. Research questions five and six focus on possible variables that may influence liking one or both of the major party candidates.

RQ5: Does following the presidential election online increase candidate likeability?

RQ6: Does online news gathering increase candidate likeability more than traditional media use?

Based on the demographic variables in the first model, those female, non-caucasian with higher levels of education would evaluate Obama more favorability. The dichotomous variable representing being black was the highest of the standardized coefficients at .30 while the predictor coefficient for those caucasian indicates a lower evaluation of the president (= -.09). According to the unstandardized coefficient, African American respondents would rate the president more than 32 points higher on the 100-point feeling thermometer. Attention and interest in the campaign did not predict an influence on how respondents rated Obama. Five of the six media variables were statistically significant with exposure to newspapers, television news, web site news and blogs all positive and similar in size ranging from .04 to .05. Obtaining news information from these sources would only slightly increase an evaluation of the incumbent. Radio news exposure lowered an evaluation of the president by a similar amount $(=-.05)$. The media variables only added .01 to the overall predictive ability of the model (total adjusted R-square of .17).

3.5 Table 2. Hierarchical Regression Analysis for Candidate Liking on Demographics, Social and other Media Variables

\begin{tabular}{|c|c|c|c|c|}
\hline \multirow[b]{3}{*}{ Independent Variables } & \multicolumn{4}{|c|}{$\frac{\text { Dependent Variable }}{2012 \text { Presidential Election }}$} \\
\hline & \multicolumn{2}{|c|}{ Thermometer: Obama } & \multicolumn{2}{|c|}{ Thermometer: Romney } \\
\hline & $\beta$ & $\mathrm{b}$ & $\beta$ & $\mathrm{b}$ \\
\hline \multicolumn{5}{|l|}{ Block 1: Demographics } \\
\hline Gender $(1=$ female $)$ & $.08 * * *$ & $5.19 * * *$ & -.01 & -.78 \\
\hline Age & -.02 & -.17 & $.08 * *$ & $.73 * *$ \\
\hline Race $(1=$ black $)$ & $.30 * * *$ & $32.79 * * *$ & $-.20 * * *$ & $-18.91 * * *$ \\
\hline Race (1= hispanic) & $.12 * * *$ & $13.23 * * *$ & -.04 & -3.89 \\
\hline Race $(1=$ caucasian $)$ & $-.09 * * *$ & $-6.62 * * *$ & $.09 * * *$ & $6.11 * * *$ \\
\hline Education & $.08 * * *$ & $2.40 * * *$ & $-.04 * *$ & $-1.07 * *$ \\
\hline Income & -.07 & -.28 & $.07 * * *$ & $.27 * * *$ \\
\hline Attention to Politics & -.03 & -.81 & .02 & .40 \\
\hline Campaign Interest & -.03 & -1.28 & $.07 * * *$ & $2.91 * * *$ \\
\hline Adjusted $\mathrm{R}^{2}$ & $.16 * * *$ & & $.10 * * *$ & \\
\hline \multicolumn{5}{|l|}{ Block 2: Media Variables } \\
\hline Exposure to Print & $.05 * *$ & $.59 * *$ & $-.04 * *$ & $-.46 * *$ \\
\hline Exposure to TV News & $.05 * * *$ & $.70 * * *$ & $.06 * * *$ & $.73 * * *$ \\
\hline Exposure to Radio News & $-.05 * * *$ & $-.66 * * *$ & $.07 * * *$ & $.81 * * *$ \\
\hline Exposure to Web News Sites & $.05 * *$ & $.57 * *$ & $-.05 * * *$ & $-.60 * * *$ \\
\hline Exposure to Social/Election & -.02 & -.25 & $.03 * *$ & $.36 * *$ \\
\hline Exposure to Blogs/Election & $.04 * *$ & $1.34 * *$ & $-.08 * * *$ & $-2.27 * * *$ \\
\hline $\mathrm{R}^{2}$ Change & $.01 * * *$ & & $.02 * * *$ & \\
\hline Total $\mathrm{R}^{2}$ & $.17 * * *$ & & $.12 * * *$ & \\
\hline Adjusted $\mathrm{R}^{2}$ & $.17 * * *$ & & $.12 * * *$ & \\
\hline
\end{tabular}


$[\beta=$ standardized coefficients, $b=$ unstandardized coefficients. Block one contains coefficients from weighted least squares regression analysis. Block two contains coefficients from the full model containing blocks one and two. Block one coefficients from the full model, although similar to those above, are not shown for purposes of brevity. Post-election $\mathrm{n}=5,510 . * \mathrm{p} \leqslant .05 \quad * * \mathrm{p} \leqslant .01 \quad * * * \mathrm{p} \leqslant .001$.

Considering the model focusing on the likeability of Mitt Romney, the demographic variables would indicate a positive relationship with age $(=.08)$, caucasian $(=.09)$, and higher levels of income $(=.07)$. The model predicts those with higher levels of education $(=-.04)$ and black $(=-.08)$ would have less positive evaluations of Mitt Romney. For example, black respondents would rate Romney almost 19 points less on the 100-point scale and those with one more level of education on the five-point scale would rate Romney one point less. Interest in the campaign would lead to higher positive evaluation levels for Romney $(=.07)$. Considering the unstandardized coefficient, one level up on the three-point interest scale would predict an increase of Romney by almost three points. All of the media variables are statistically significant, ranging from -.08 to .07 . Of the media variables, reading newspapers $(=-.04)$, online news $(=$ $-.05)$, and blogs $(=-.08)$ all would decrease evaluations of Romney. Individuals who receive news information from radio $(=.07)$, television $(=.06)$ and social media $(=.03)$ would rate the candidate higher. The media variables added .02 to the full model's adjusted R-square of .12.

\section{Discussion}

\subsection{Implications and Context with Previous Research}

Blogs and web site visits for political information supported a greater sense of confidence to understand policy issues but had no relationship with respondents feeling government is too complex to comprehend. This finding seems to support research about the credibility of blogs for information seeking and how many online sources now have credibility levels rivaling traditional media (Johnson \& Kaye, 2010). Interestingly, the other form of media deemed to be highly credible in previous research - print newspapers - was found here to reduce the complexity of government but no support exists for a similar reduction to allow better understanding of policy issues (Johnson \& Kaye, 2010). Other researchers in the last election found a positive relationship between radio listening and using web sites for political information seeking (Parmelee, Davies \& McMahan, 2011). The political understanding measure in 2012 also allows for this possibility although it was not directly investigated. In this study, exposure to radio news and web news sites were both positive predictors leading to a greater sense of understanding important issues. While one may consider this a result of Republican listeners of political talk (e.g. Rush Limbaugh) who then seek out web site news that support their political orientation and lead to greater understanding, this consideration is not supported by the coefficients measuring liking individual candidates. While regular listening of radio news did increase the positive evaluations of Romney and lowered those for Obama, an opposite relationship was found for getting news online. Those that regularly visited online news sites had higher evaluations of Obama and lower ones of Romney. Confidence in understanding policy issues and candidate likeability are very different variables and their relationship should be examined in future elections.

The 2012 data analyzed supports the influence of existing traditional media predicting political talk. As Emmer, Wolling and Vowe found in an election in Germany, face-to-face political discussion often resulted from print and television news seeking (2012). Similarly, in 2012 television news and radio predicted political talk but, unlike most of the elections in the previous study, online communication -- in the form of web sites, social media and blogs -- would also contribute to interpersonal discussion. The study here does support previous research that multiple media predictors lead to additional personal communication about politics (Tian, 2011).

The final research questions attempted to determine the role of online communication versus their traditional counterparts. The results show media sources are much too complicated to be categorized in that way. While some similarity exists, each is unique and should not be considered within or across these broad categories. For example, of the six media variable relationships analyzed with likeability two are negative for Obama evaluations and a different three are negative for Romney evaluations. These results point to the unique nature of each medium but also their capacity to influence evaluations of candidates differently. Future research should examine more micro-level analyses to determine why one medium may be advantageous to promote a particular issue or candidate.

\subsection{Limitations and Future Research}

Limitations of using any large data set is the inability to do micro-level analyses as described above but these analyses should be considered for future elections. Also, other researchers have investigated what increases in political discussion lead to next and its interaction with other media (Feldman \& Price, 2008; Ikeda \& Boase, 2011; Eveland \& Lively, 2009). Both of these areas offer significant promise to better triangulate discussion with other campaign processes. Similarly, communication scholars have only recently begun investigating social media and its own interaction with other media also holds the potential to better understand media processes. 


\section{References}

ANES. (2013). User's guide and codebook for the ANES 2012 time series study. Ann Arbor, MI \& Palo Alto, CA: University of Michigan and Stanford University.

Boyle, T. P. (2013). 2008 presidential campaign media predictors: Interest, issue knowledge and candidate likeability. Atlantic Journal of Communication, 21(2), 95-107. http://dx.doi.org/10.1080/15456870.2013.773481

Bennett, W. L., \& Manheim, J. B. (2006). The one-step flow of communication. The annals of the American Academy of Political and Social Science, 608, 213-232. http://dx.doi.org/10.1177/0002716206292266

de Zúñiga, H. G. (2012). Social media use for news and individuals’ social capital, civic engagement and political participation. Journal of Computer-Mediated Communication, $17, \quad 319-336$. http://dx.doi.org/10.1111/j.1083-6101.2012.01574.x

Dalton, R. J. (2007). The good citizen: How a younger generation is reshaping American politics. Washington, D.C.: CQ Press.

Dylko, I., \& McCluskey, M. (2012). Media effects in an era of rapid technological transformation: A case of user-generated content and political participation. Communication Theory, 22, 250-278. http://dx.doi.org/10.1111/j.1468-2885.2012.01409.x

Emmer, M., Wolling, J., \& Vowe, G. (2012). Changing political communication in Germany: Findings from a longitudinal study on the influence of the internet on political information, discussion and the participation of citizens. Communications 2012, 37(3), 233-252.

Eveland Jr., W. P. (2004). The effect of political discussion in producing informed citizens: the role of information, motivation, and elaboration. Political Communication, $21, \quad$ 177-193. http://dx.doi.org/10.1080/10584600490443877

Eveland Jr., W. P., \& Hutchens Hively, M. (2009). Political discussion frequency, network size, and "heterogeneity" of discussion as predictors of political knowledge and participation. Journal of Communication, 59, $205-224$. http://dx.doi.org/10.1111/j.1460-2466.2009.01412.x

Eveland Jr., W. P., Morey, A. C., \& Hutchens, M. J. (2011). Beyond deliberation, New directions for the study of informal political conversation from a communication perspective. Journal of Communication, 61, 1082-1103. http://dx.doi.org/10.1111/j.1460-2466.2011.01598.x

Feldman, L., \& Price, V. (2008). Confusion or enlightenment? How exposure to disagreement moderates the effects of political discussion and media use on candidate knowledge. Communication Research, 35(1), 61-87. http://dx.doi.org/10.1177/0093650207309362

Hardy, B. W., \& Scheufele, D. A. (2009). Presidential campaign dynamics and the ebb and flow of talk as a moderator: Media exposure, knowledge, and political discussion. Communication Theory, 19, 89-101. http://dx.doi.org/10.1111/j.1468-2885.2008.01334.x

Hargittai, E., \& Shaw, A. (2013). Digitally savvy citizenship: The role of internet skills and engagement in your adults' political participation around the 2008 presidential election. Journal of Broadcasting \& Electronic Media, 57(2), 115-134. http://dx.doi.org/10.1080/08838151.2013.787079

Himelboim, I., Lariscy, R. W., Tinkham, S. F., \& Sweetser, K. D. (2012). Social media and online political communication: The role of interpersonal informational trust and openness. Journal of Broadcasting \& Electronic Media, 56(1), 92-115. http://dx.doi.org/10.1080/08838151.2011.648682

Houston, J. B., Hawthorne, J., Spialek, M. L., Greenwood, M., \& McKinney, M. S. (2013). Tweeting during presidential debates: Effect on candidate evaluations and debate attitudes. Argumentation and Advocacy, 49, 301-311.

Ikeda, K., \& Boase, J. (2011). Multiple discussion networks and their consequence for political participation. Communication Research, 38(5), 660-683. http://dx.doi.org/10.1177/0093650210395063

Johnson, T., \& Kaye, B. (2010). Choosing is believing? How web gratifications and reliance affect internet credibility among politically interested users. Atlantic Journal of Communication, 18, 1-21. http://dx.doi.org/10.1080/15456870903340431

Kaye, B. K., \& Johnson, T. J. (2002). Online and in the know: Uses and gratifications of the web for political information. Journal of Broadcasting \& Electronic Media, $46(1), \quad 54-71$. http://dx.doi.org/10.1207/s15506878jobem4601_4 
Kaye, B. K., \& Johnson, T. J. (2011). Hot diggity blog: A cluster analysis examining motivations and other factors for why people judge different types of blogs as credible. Mass Communication and Society, 14, 236-263. http://dx.doi.org/10.1080/15205431003687280

Metzgar, E., \& Maruggi, A. (2009). Social media and the 2008 U.S. presidential election. Journal of New Communications Research, 4(1), 141-165.

Moy, P., \& Gastil, J. (2006). Predicting deliberative conversation: The impact of discussion networks, media use, and political cognitions. Political Communication, 23, 443-460. http://dx.doi.org/10.1080/10584600600977003

Moyer, A. C., Eveland, Jr., W. P., \& Hutchens, M. J. (2012). The "who" matters: Types of interpersonal relations and avoidance of political disagreement. Political Communication, 29, 86-103. http://dx.doi.org/10.1080/10584609.2011.641070

Parmelee, J. H., Davies, J., \& McMahan, C. A. (2011). The rise of non-traditional site use for online political information. Communication Quarterly, 59(5), 625-640. http://dx.doi.org/10.1080/01463373.2011.614211

Rainie, L. (2012, November). Social media and voting Retrieved from http://www.pewinternet.org/Reports/2012/Social-Vote-2012.aspx

Rainie, L., \& Smith, A. (2012, September). Politics on social networking sites. Retrieved from http://www.pewinternet.org/Press-Releases/2012/Politics-on-Social-Networking-Sites.aspx

Rainie, L., Smith, A., Lehman Schlozman, K., Brady, H. \& Verba, S. (2012, October). Social media and political engagement. Retrieved from http://www.pewinternet.org/Reports/2012/Political-engagement.aspx

Tian, Y. Communication behaviors as mediators: Examining links between political orientation, political communication, and political participation. Communication Quarterly, 59(3), 380-394. http://dx.doi.org/10.1080/01463373.2011.583503

Utz, S. (2009). The (potential) benefits of campaigning via social network sites. Journal of Computer-Mediated Communication, 14, 221-243. http://dx.doi.org/10.1111/j.1083-6101.2009.01438.x

Weaver, D., \& Drew, D. (2001). Voter learning and interest in the 2000 presidential election: Did the media matter? Journalism \& Mass Communication Quarterly, 72(1), 7-17. http://dx.doi.org/10.1177/107769909507200102

Winograd, M., \& Hais, M. D. (2008). Millennial makeover: MySpace, YouTube, and the future of American politics. New Brunswick, NJ: Rutgers University Press.

\section{$(c)) B Y$}

This work is licensed under a Creative Commons Attribution 3.0 License. 